\title{
The Impacts of Integrated Health Hydroponic Planting On Green Space Exposure, Happiness, Anxiety and Stress Among Secondary School Students: A Feasibility Quasi-Experiment
}

\section{Stephen Wai Hang Kwok}

Hong Kong Polytechnic University

Yim Wah Mak

Hong Kong Polytechnic University

Alice Pui Ying Chiu

Hong Kong Polytechnic University

Yan Kit Chong

Hong Kong Polytechnic University

Lorna Kwai Ping Suen

Hong Kong Polytechnic University

Edmond Kam

Hong Kong Polytechnic University

Cecilia K.C. Wong

Hong Kong Polytechnic University

Cynthia Sau Ting Wu ( $\nabla$ cynthia.wu@polyu.edu.hk)

Hong Kong Polytechnic University

\section{Research Article}

Keywords: adolescents, hydroponic-planting, stress management, quasi-experiment, green space, anxiety, stress, happiness

Posted Date: June 2nd, 2021

DOI: https://doi.org/10.21203/rs.3.rs-534205/v1

License: (c) (i) This work is licensed under a Creative Commons Attribution 4.0 International License. Read Full License 


\section{Abstract}

Background: Mental health of adolescents have been exposing to risk factors associated with stress from a variety of sources. Previous studies identified that green space exposure might be effective for promoting mental health and reduction of stress. However, previous literature focused on adults, and for those which studied children and adolescents, the effects of planting and similar green activities remain to be explored. The aim of this study was to investigate the effects of a pioneer school-based program on green space use and satisfaction, and mental wellbeing indicators, among early adolescent students.

Methods: This was a feasibility quasi-experiment in which intervention and control groups were studied sequentially. Three secondary schools and 55 grade 7-8 students were sampled conveniently. In the intervention school, the green space program consists of learning hydroponic planting and group practice in creating green areas at school. In the two control schools, the activities consisted of a standardized stress management program including relaxation exercise such as stretching, extension and massage. Both groups learned green diet, tasting and had green living activity, stress awareness games and learned stress coping. The activity schedule for each group (intervention and control) consisted of three one-hour sessions, each was conducted two to three weeks apart. Key outcomes were assessed with questionnaires at baseline and one month after the completion of the activity period as for each school. Data were fit with mixed model applying GEE.

Results: At baseline, students were not sure whether they know how to plant herbs or prepare herbal tea. Control group at posttest had lower frequencies of using green facilities in the community and using school gardening facilities in the previous four weeks compared with intervention group and pretest. Females at posttest were associated with higher confidence in planting, and higher level of enjoyment from green activities. Other moderate to small but non-significant effects were also identified.

Conclusions: In this study, the school-based green space programme was found feasible for early adolescent students with statistically supported results. Limitations have also been identified and future study with larger scale, more frequent intervention, longer follow-up and RCT design are required.

\section{Background}

Adolescent secondary school students are faced with multi-dimensional physical and psychological challenges that could impact on their mental well-being. They are at an adolescent development stage, and need to cope with abrupt changes in their physical bodies. They are often under inter-personal pressure in forming new social relationships [1]. Academic pressure is also an important source of stress which affect mental health [2,3]. Most local students seek to relieve stress through engagement in physical activities, seeking peer support or listening to or engaging in music [4]. Yet, green space, gardening, horticultural and similar activities were found having positive effects on mental health.

In the literature, there were a number of evidence which show the association between green space and its related human activities and health. Urban greenery and water were deemed important elements to 
improve indoor air quality, temperature and protection against heat and cold, which have effects on both physical and psychosocial health [5]. Research evidence with multiple angles in terms of neuroimaging data and supporting cellular and molecular animal studies indicated the interaction between social and environmental risk factors of mental health [6].

In the community, adults who lived closer to green space had lower perceived stress, better perceived health and related quality of life (QoL), and were more likely to use green space for relaxation [7]. According to a review done in 2013 [8], adults with mental health issues had their depression and anxiety reduced, and benefited in physical, emotional, social, spiritual and even vocational domains after joining gardening activities. In Hong Kong, researchers found that horticultural activity could improve psychiatric patients' level of anxiety, depression and stress in a randomized controlled trial (RCT) [9]. The above evidence imply that human activities associated with plants for aesthetics could have positive effects on mental health.

Longitudinal evidence indicated that health benefits from green area appeared in different life courses between genders. In men, benefit of more green space emerged in early to mid-adulthood [10]. In women, but at older ages, moderate availability of green space was found contributing to better mental health. More benefits of green space might extend to physical health also. Previous study showed that cardiovascular disease and respiratory disease mortality rates decreased with increasing green space, but in men only [11]. Yet, women were found more active, saw greater aesthetic value, and had higher selfreported wellbeing in urban green spaces than men [12]. However, these gender differences were not confirmed in adolescents who would participate in green activities. Outdoor green space was found facilitating protective factors of health such as increased free-time physical activity level in early adolescents [13]. Previous study also showed that neighborhood parks was associated with reduced stress among adolescents regardless of socio-economic status (SES) [14]. Nonetheless, the mental health benefits of gardening, horticulture or similar activities on adolescents needed further studies.

Due to increasing urbanization and densification in Hong Kong, most students live far away from green space. Hydroponics is a method of plants growing in a flexible scale with the use of water-based, nutrientrich solution. With proper care, the plants can grow fast and strong by using less water; and hydroponics plants are more environment friendly than soil-based plants $[15,16]$. Hydroponics in the green roof systems are potentially applicable in Hong Kong building for example the schools in which adolescents spent most of their time [17].

Whether having green space at schools could provide them, however, a means for stress reduction or help them develop a green-living attitude and behavior remained unclear. Earlier studies investigated the effects of green space programs holistically, but the specific effects had remained unexplored to date. There was also limited research on the relationships between green space, gender differences on mental health in secondary school students. Thus, the aim of this study was to investigate the impact of a pioneer school green space program on selected mental health indicators in secondary school students after participating in either the designed program or control activities with follow up. 


\section{Hypothesis}

It is hypothesized that after participation in the green space programme, students' will have their green space exposure and mental wellbeing in terms of 1) green space use and satisfaction, 2) anxiety and stress symptoms, 3 ) level of happiness improved compared with those who joined control activities.

\section{Methods}

\section{Design}

This was a feasibility quasi-experiment in which there was one intervention school and two control schools. Activities were conducted in each school sequentially.

\section{Eligibility criteria and sampling}

The eligibility criteria of schools were 1) secondary schools in Hong Kong, 2) having a potential venue for hydroponic planting, 3) allowing students to participate in extracurricular activities. The eligibility criteria of students were 1) secondary school students (grade 7-8), 2) able to communicate in Chinese, 3) no allergy to soil, pollens or plants, 4) no G6PD deficiency.

Convenience sampling was done to sequentially recruit the first control school in Feb 2018, and the second control school and the intervention school in Sep 2018. The intervention school was the one which showed interest in installing hydroponic planting system. One control school comprised three classes for each grade, and the other schools consisted of four classes for each grade. Each class contained 33 students. One class from grade 7 and one class from grade 8 were randomly recruited by the teacher in each school. Students in each recruited class were then conveniently recruited. Before the study activities, students with consents were screened for eligibility criteria on a checklist. Those who did not satisfy any one of the criteria were not included.

\section{Intervention}

In the intervention group, the program, run by undergraduates who were trained by hydroponic planting therapist, consisted of (1) learning green diet, tasting and green living activity; (2) stress awareness games (15 min quiz) and learning stress coping; and (3) learning hydroponic planting and group practice in creating green areas at school. The content included the introduction of basic techniques of planting, including material choosing, seeding, and watering; with materials provided for students to do hands-on planting. The theory part was taught in classroom with standardized slideshow (18 slides); and the practice session was held in the playground. The school was provided with hydroponic planting devices for the practice sessions. In addition, one teacher was trained for the technique of planting and the management of green plants, in order to guide the students for a sustainable green space at school.

The control group consisted of a standardized classroom-based stress management program of (1) learning green diet, tasting and green living activity; (2) stress awareness games and learning stress 
coping; and (3) relaxation exercise including stretching, extension and massage. The students were supervised and guided by trained undergraduates from The Hong Kong Polytechnic University.

The activity schedule for each group (intervention and control) consisted of three one-hour sessions, each was conducted two to three weeks apart. The research activity period for the first control school was from Mar 2018 to Jun 2018; the period for the second control school and intervention school was from Oct to Dec 2018.

\section{Outcomes}

Key outcomes which were assessed at baseline and posttest included 1) green space use and satisfaction, 2) anxiety and stress, 3) happiness. Questionnaires which measure all targeted outcomes were distributed to both groups at baseline and one month after the completion of the activity period as for each school. Another outcome assessed at baseline was the green dietary habits. Students were blinded to study hypothesis though not blinded to activities they have participated in.

\section{Green space use and satisfaction}

Green space use and satisfaction was assessed in three domains, they were 1) level of exposure to green space (four items)[18-21]; 2) perceived benefits of green activities (three items)[22, 23]; 3) satisfaction of green space available (four items)[24]. Each item was measured by a four-point ordinal scale. Higher score indicates more frequent green space use in the past four weeks or level of agreement. The instrument was developed by the research team based on literature review. Its content validity was assessed by three experts in occupation health, mental health nursing, and community health nursing, respectively, who had extensive experiences in promoting healthy lifestyle at school. They independently rated the relevance of each item by using a four-point scale. The Content Validity Index for Items (I-CVIs) was high $(\mathrm{I}-\mathrm{CVI}=0.98)$. Test-retest reliability was assessed on ten participants who completed the same questionnaire two weeks apart. The reliability was satisfactory $(r=0.764)$. The scale reliability (internal consistency) at baseline was acceptable (Cronbach's alpha $=.755, n=55$ ).

\section{Anxiety and stress}

The self-reported anxiety and stress symptoms of the participants were measured by the corresponding subscales in the Depression Anxiety Stress Scale (DASS) (21 items) which was freely provided by the Psychology Foundation of Australia [25-27]. Each subscale comprised seven items which measure either anxiety, stress or depressive symptoms in the past week. Respondents were asked to rate each statement on a four-point ordinal scale from $0=$ not applicable to $3=$ most applicable. Higher score indicates more severe symptoms. DASS-21 showed satisfactory internal consistency and three-factor structure in Asian [28] including Chinese young populations [29].

\section{Happiness}

Happiness was measured by the Delighted-Terrible Faces (DT-Faces) Scale which is a seven-point ordinal visual analogue scale (VAS) [30]. The score ranged from $1=$ most happy (face A) to 7 = most unhappy 
(face $\mathrm{G}$ ).

\section{Green dietary habits}

Green dietary habits were assessed with five items at baseline, they were the level of agreement on knowing how to grow edible plants, understanding, habit and promotion of green diet. Each item was measured with a four-point ordinal scale. Higher score indicates better habits.

\section{Data analyses}

Questionnaires at baseline and posttest were matched using the class and class number of students in each school. Categorical demographic characteristics included sex, cohabitants, religion and housing. Between group differences in these characteristics were tested with Fisher exact tests [31]. Continuous demographic characteristics included age, years living in Hong Kong, and amount of pocket money got per week. Between group differences in these variables were tested with independent $t$ tests [32]. Between group differences in green dietary habits at baseline were tested with Wilcoxon rank sum tests [33]. The group, time, sex effects and their interactions on green space use and satisfaction and mental wellbeing in terms of stress, anxiety and happiness were tested with generalized estimating equations (GEE) [34]. Error distribution was assumed following the Gaussian family. The correlation structure between time points was specified as first order autoregressive (AR1). Significance level (alpha) was set at .05. All analyses were done on $\mathrm{R}$ version 4.0.3 on RStudio 1.4.1103.

\section{Results}

At baseline, 59 students were recruited in total. The period of recruitment and follow-up fell between Feb 2018 and Dec 2018. There were 18 students in the intervention school and 41 students in the control schools. At posttest, four students dropped out from the control group, hence the final number analyzed was 55 .

Demographic characteristics were presented in Table 1. There were no significant between-group differences in sex, cohabitants, religion, housing, age, years living in Hong Kong, except living with maternal grandmother and the amount of pocket money received per week. However, the number of those living with maternal grandmother was small. Though the mean pocket money in control group was higher, the dispersion was also greater. Overall, the mean age of the sample was $13.5(S D=0.81), 60 \%$ of the sample were males, and over $60 \%$ were living in public housing. Over three-fourths did not have religious belief. Above $90 \%$ were living with mother but only three-fourths lived with father. Sixty percent of the sample were living with siblings. A majority of the participants were not living with grandparents. 
Table 1

Demographic characteristics

Intervention Control

Fisher exact

\begin{tabular}{|c|c|c|c|c|}
\hline & & $N=18$ & $N=37$ & $\mathrm{p}$ \\
\hline \multirow[t]{2}{*}{ Sex } & $1=$ male & 8 & 25 & 0.14 \\
\hline & $2=$ female & 10 & 12 & \\
\hline \multirow[t]{2}{*}{ Live with father } & $1=$ yes & 14 & 27 & 1 \\
\hline & $2=$ no & 4 & 10 & \\
\hline \multirow[t]{2}{*}{ Live with mother } & $1=$ yes & 16 & 35 & 0.59 \\
\hline & $2=$ no & 2 & 2 & \\
\hline \multirow[t]{2}{*}{ Live with siblings } & $1=$ yes & 12 & 21 & 0.57 \\
\hline & $2=$ no & 6 & 16 & \\
\hline \multirow[t]{4}{*}{ Live with number of siblings } & 0 & 6 & 16 & 0.059 \\
\hline & 1 & 4 & 15 & \\
\hline & 2 & 7 & 5 & \\
\hline & 4 & 1 & 0 & \\
\hline \multirow[t]{2}{*}{ Live with paternal grandfather } & $1=$ yes & 3 & 1 & 0.098 \\
\hline & $2=$ no & 15 & 36 & \\
\hline \multirow[t]{2}{*}{ Live with paternal grandmother } & $1=$ yes & 7 & 7 & 0.19 \\
\hline & $2=$ no & 11 & 30 & \\
\hline \multirow[t]{2}{*}{ Live with maternal grandfather } & $1=$ yes & 0 & 1 & 1 \\
\hline & $2=$ no & 18 & 36 & \\
\hline \multirow[t]{2}{*}{ Live with maternal grandmother } & $1=$ yes & 3 & 0 & 0.031 \\
\hline & $2=$ no & 15 & 37 & \\
\hline \multirow[t]{2}{*}{ Live with others } & $1=$ yes & 1 & 1 & 1 \\
\hline & 2 = no & 17 & 36 & \\
\hline \multirow[t]{2}{*}{ Live with number of others } & 0 & 18 & 36 & 1 \\
\hline & 1 & 0 & 1 & \\
\hline Religion & $1=$ nil & 13 & 29 & 0.66 \\
\hline
\end{tabular}




\begin{tabular}{|lllll|}
\hline & & Intervention & Control & Fisher exact \\
\hline & 2 = Buddhism & 2 & 1 & \\
\hline 3 = Catholic & 0 & 1 & \\
\hline 4 = Protestant & 3 & 6 & \\
\hline Housing & 1 = public & 11 & 23 & 1 \\
\hline 2 = non-public & 7 & 14 & Welch t test \\
\hline Age & & Intervention & Control & p \\
\hline Years living in Hong Kong & Mean (SD) & Mean (SD) & 0.55 \\
\hline Pocket money per week & & $13.39(0.92)$ & $13.54(0.77)$ & 0.21 \\
\hline
\end{tabular}

In Table 2, it shows that the green dietary habits at baseline did not have significant between-group differences. Generally, both groups agreed that they could understand the importance of balanced diet, consume optimal portions of vegetables, and encourage the others to follow green eating. However, students in the intervention group were not sure whether they know how to plant herbs or prepare herbal tea. Participants in the control group disagreed that they know how to plant vegetables or herbs or prepare herbal tea.

Table 2

Green dietary habits at baseline

\begin{tabular}{|llllll|}
\hline & Intervention & \multicolumn{2}{c}{ Control } & & Wilcoxon \\
\hline & Median & MAD & Median & MAD & p \\
\hline I know how to plant vegetables & 3 & 0 & 2 & 0 & 0.12 \\
\hline $\begin{array}{l}\text { I know how to plant herbs and make herbal } \\
\text { tea }\end{array}$ & 2.5 & 0.74 & 2 & 0 & 0.080 \\
\hline I can eat three portions of vegetables per day & 3 & 0 & 3 & 1.48 & 0.10 \\
\hline I know the importance of a balanced diet & 3 & 0 & 3 & 0 & 0.067 \\
\hline I encourage others to follow green eating & 3 & 0 & 3 & 0 & 0.81 \\
\hline MAD: median absolute deviation & & & & & \\
\hline
\end{tabular}

Table 3 shows the effects of group, time and sex and their interactions on green space use and satisfaction as well as mental wellbeing in terms of stress, anxiety and happiness scores. The group by time effect on the using green facilities in the community and the using school gardening facilities were 
significant; where control group at posttest had lower frequencies of these activities in the previous four weeks compared with intervention group and pretest. Other moderate to small but non-significant effects included those on other outcomes such as happiness level, satisfaction with the green facilities in the community, and feeling relaxed when using the green facilities. We also see significant sex by time effect on the confidence in planting correctly, feeling relaxed when using the green facilities, and feeling happy when looking at their own plants. Females at posttest were associated with higher confidence in planting, and higher level of enjoyment from green activities. 
Table 3

Green space use and satisfaction and mental wellbeing regressed on group, time and sex

\begin{tabular}{|c|c|c|c|c|c|c|}
\hline & (Intercept) & Control & $\begin{array}{l}\text { Post- } \\
\text { test }\end{array}$ & Female & $\begin{array}{l}\text { Control } \\
\text { at post- } \\
\text { test }\end{array}$ & $\begin{array}{l}\text { Female } \\
\text { at post- } \\
\text { test }\end{array}$ \\
\hline & b (SE) & b (SE) & b (SE) & b (SE) & b (SE) & $\mathrm{b}(\mathrm{SE})$ \\
\hline $\begin{array}{l}\text { Use green facilities in the } \\
\text { community in the past four } \\
\text { weeks }\end{array}$ & $\begin{array}{l}0.66 \\
(0.22)^{\star \star}\end{array}$ & $\begin{array}{l}0.25 \\
(0.25)\end{array}$ & $\begin{array}{l}0.35 \\
(0.34)\end{array}$ & $\begin{array}{l}0.11 \\
(0.26)\end{array}$ & $\begin{array}{l}-0.74 \\
(0.35)^{\star}\end{array}$ & $\begin{array}{l}-0.13 \\
(0.34)\end{array}$ \\
\hline $\begin{array}{l}\text { Visit green space of your } \\
\text { school in the past four weeks }\end{array}$ & $\begin{array}{l}0.55 \\
(0.28)^{\star}\end{array}$ & $\begin{array}{l}-0.09 \\
(0.29)\end{array}$ & $\begin{array}{l}-0.22 \\
(0.31)\end{array}$ & $\begin{array}{l}0.41 \\
(0.28)\end{array}$ & $\begin{array}{l}0.17 \\
(0.33)\end{array}$ & $\begin{array}{l}-0.01 \\
(0.34)\end{array}$ \\
\hline $\begin{array}{l}\text { Use school gardening facilities } \\
\text { in the past four weeks }\end{array}$ & $\begin{array}{l}0.16 \\
(0.14)\end{array}$ & $\begin{array}{l}0.11 \\
(0.18)\end{array}$ & $\begin{array}{l}0.39 \\
(0.2)\end{array}$ & $\begin{array}{l}0.51 \\
(0.22) \star\end{array}$ & $\begin{array}{l}-0.67 \\
(0.24)^{\star \star}\end{array}$ & $\begin{array}{l}-0.29 \\
(0.25)\end{array}$ \\
\hline $\begin{array}{l}\text { I know the location of the green } \\
\text { space facilities at school }\end{array}$ & $\begin{array}{l}1.66 \\
(0.23) \star \star \star\end{array}$ & $\begin{array}{l}-0.19 \\
(0.25)\end{array}$ & $\begin{array}{l}0.12 \\
(0.32)\end{array}$ & $\begin{array}{l}0.31 \\
(0.27)\end{array}$ & $\begin{array}{l}0.04 \\
(0.32)\end{array}$ & $\begin{array}{l}0.08 \\
(0.32)\end{array}$ \\
\hline $\begin{array}{l}\text { I have confidence in planting } \\
\text { correctly }\end{array}$ & $\begin{array}{l}2.07 \\
(0.06) * \star \star\end{array}$ & $\begin{array}{l}0.11 \\
(0.09)\end{array}$ & $\begin{array}{l}-0.44 \\
(0.14)^{\star \star}\end{array}$ & $\begin{array}{l}-0.22 \\
(0.1)^{*}\end{array}$ & $\begin{array}{l}-0.11 \\
(0.15)\end{array}$ & $\begin{array}{l}0.58 \\
(0.16)^{\star \star *}\end{array}$ \\
\hline $\begin{array}{l}\text { I think that green living lifestyle } \\
\text { can promote concentration }\end{array}$ & $\begin{array}{l}1.85 \\
(0.2)^{\star \star \star}\end{array}$ & $\begin{array}{l}0.08 \\
(0.18)\end{array}$ & $\begin{array}{l}-0.18 \\
(0.24)\end{array}$ & $\begin{array}{l}-0.03 \\
(0.15)\end{array}$ & $\begin{array}{l}-0.08 \\
(0.23)\end{array}$ & $\begin{array}{l}0.23 \\
(0.21)\end{array}$ \\
\hline $\begin{array}{l}\text { Green school program can } \\
\text { promote communication }\end{array}$ & $\begin{array}{l}2.04 \\
(0.12) \star \star \star\end{array}$ & $\begin{array}{l}-0.13 \\
(0.14)\end{array}$ & $\begin{array}{l}-0.32 \\
(0.22)\end{array}$ & $\begin{array}{l}0.03 \\
(0.15)\end{array}$ & $\begin{array}{l}0.02 \\
(0.22)\end{array}$ & $\begin{array}{l}0.17 \\
(0.21)\end{array}$ \\
\hline $\begin{array}{l}\text { I am satisfied with the current } \\
\text { green space in school }\end{array}$ & $\begin{array}{l}1.67 \\
(0.16) \star \star \star\end{array}$ & $\begin{array}{l}0.03 \\
(0.18)\end{array}$ & $\begin{array}{l}0.4 \\
(0.17) \star\end{array}$ & $\begin{array}{l}-0.01 \\
(0.18)\end{array}$ & $\begin{array}{l}-0.2 \\
(0.2)\end{array}$ & $\begin{array}{l}-0.01 \\
(0.21)\end{array}$ \\
\hline $\begin{array}{l}\text { I feel relaxed when I use the } \\
\text { green facilities }\end{array}$ & $\begin{array}{l}1.99 \\
(0.17)^{\star \star \star}\end{array}$ & $\begin{array}{l}0.09 \\
(0.17)\end{array}$ & $\begin{array}{l}-0.66 \\
(0.26)^{\star}\end{array}$ & $\begin{array}{l}-0.09 \\
(0.17)\end{array}$ & $\begin{array}{l}0.31 \\
(0.25)\end{array}$ & $\begin{array}{l}0.58 \\
(0.22) \star \star\end{array}$ \\
\hline $\begin{array}{l}\text { I feel happy when I look at my } \\
\text { plants }\end{array}$ & $\begin{array}{l}2.13 \\
(0.14)^{\star \star \star *}\end{array}$ & $\begin{array}{l}-0.01 \\
(0.14)\end{array}$ & $\begin{array}{l}-0.37 \\
(0.18)^{*}\end{array}$ & $\begin{array}{l}-0.03 \\
(0.13)\end{array}$ & $\begin{array}{l}0.09 \\
(0.18)\end{array}$ & $\begin{array}{l}0.37 \\
(0.18)^{*}\end{array}$ \\
\hline $\begin{array}{l}\text { I am satisfied with the green } \\
\text { facilities in the community }\end{array}$ & $\begin{array}{l}1.62 \\
(0.22)^{\star \star \star}\end{array}$ & $\begin{array}{l}0.3 \\
(0.23)\end{array}$ & $\begin{array}{l}0.25 \\
(0.23)\end{array}$ & $\begin{array}{l}0.08 \\
(0.22)\end{array}$ & $\begin{array}{l}-0.41 \\
(0.26)\end{array}$ & $\begin{array}{l}0.16 \\
(0.25)\end{array}$ \\
\hline Mean of stress score & $\begin{array}{l}0.46 \\
(0.15)^{\star \star}\end{array}$ & $\begin{array}{l}0.14 \\
(0.16)\end{array}$ & $\begin{array}{l}0.31 \\
(0.23)\end{array}$ & $\begin{array}{l}0.04 \\
(0.15)\end{array}$ & $\begin{array}{l}-0.14 \\
(0.24)\end{array}$ & $\begin{array}{l}-0.15 \\
(0.23)\end{array}$ \\
\hline Mean of anxiety score & $\begin{array}{l}0.46 \\
(0.14)^{\star \star \star}\end{array}$ & $\begin{array}{l}0.04 \\
(0.15)\end{array}$ & $\begin{array}{l}0.25 \\
(0.22)\end{array}$ & $\begin{array}{l}0.05 \\
(0.13)\end{array}$ & $\begin{array}{l}-0.13 \\
(0.23)\end{array}$ & $\begin{array}{l}-0.12 \\
(0.22)\end{array}$ \\
\hline Happiness level & $\begin{array}{l}2.92 \\
(0.33) \star \star \star\end{array}$ & $\begin{array}{l}-0.06 \\
(0.35)\end{array}$ & $\begin{array}{l}-0.52 \\
(0.44)\end{array}$ & $\begin{array}{l}-0.25 \\
(0.35)\end{array}$ & $\begin{array}{l}0.57 \\
(0.47)\end{array}$ & $\begin{array}{l}-0.06 \\
(0.48)\end{array}$ \\
\hline
\end{tabular}




\section{Limitations}

The major limitation in this study was that the sample size was not large, and the balance between groups was further complicated by group allocation as there was only one set of hydroponic planting device. As seen in the results, the number included in the intervention group was 18 and the number in control group was 37, though the sample size of 55 was considered for parametric tests. But, for example, in crosstabs, some cell counts were small that favor Fisher exact test over chi-squared. Another limitation related to smaller sample size was lower statistical power. For example, in the GEE model, some estimates with moderate effect sizes (moderately strong coefficients) were non-significant.

Regarding the assessment of green space use and satisfaction, the number analyzed in test-retest reliability was small, and validities such as convergent, concurrent and factor structure validity require further study.

On the other hand, recall bias and effect contamination might existed since the posttest was done one month after the last day of activity period for each school. Participants in the community might be exposed to different confounders over time as research activities were not run in parallel for all schools. For example, control group participants might or might not join green activities themselves in the window period. Therefore, future RCT is required.

\section{Generalizability}

The generalizability of the study results and intervention might be compromised by non-random sampling, and the combined limitations of group allocation and sample size, and the limitations in assessment tool and schedule. However, the report of this study supports that hydroponic planting is a feasible intervention for adolescents in school setting with potential and statistical positive outcomes in terms of green space use, satisfaction, and mental wellbeing.

\section{Interpretations}

The hypothesis regarding the improvements, after participating in hydroponic planting, in green space use and satisfaction was partially supported; and the hypothesis with respect to mental wellbeing requires further investigation. However, some of the results related to gender difference are somehow consistent with the literature that females, over time, were more emotionally and confidently engaged in green activities. The non-significant group by time effects for the variables in terms of mental wellbeing might support an interpretation that the effects of hydroponic planting might be comparable to those of control activities, as stress reduction intervention was also provided in the control group. Another reason that we did not find significant group by time effects on mental wellbeing might be that students recruited were from general population which were not patients or at-risk groups recognized. However, future studies could focus on these groups to examine the benefits of hydroponic planting on them. Further, the frequency and period of intervention could be lengthened. One-hour session for every two to three weeks for three times might not be frequent enough to allow significant differences between groups. In addition, there was no post-test for green dietary habits. Future studies should answer these related questions. 
In the competitive education system worldwide, sources of pressure for school children could be from too much homework, long school hours and preparation for secondary school entry and/or unsatisfactory school performance $[35,36]$. Green space exposure and green activities could minimize the mental health risks. Previous evidence shows that during childhood, risk for subsequent mental illness in those who lived with the lowest level of green space exposure was higher compared with those who lived with the highest level of exposure [37]. Stronger association was observed in cumulative exposure compared with single-year exposure. A Dutch survey discovered that households with a high volume of green space within three $\mathrm{km}$ radius were less affected by experiencing stressful life event, and potentially the perceived mental health issues [38].

Nonetheless, the use of public green space could be affected by demographic factors such as gender, lifestyle, family background. In a cross-sectional study of Dutch [39], adolescents reported that green environment was very important for them to visit green spaces frequently for physical and social activities. In particular, males, those who owned dogs, or those having educated father visited green spaces more often. However, the visits were not associated with the quantity of green space around the residential area. A German survey showed a non-linear (inverted U-shape) relationship between the amount of and distance to green space and life satisfaction in urban residents [40].

At school setting, school based green activities were considered feasible interventions for students' wellbeing. However, previous results, including findings in this study, render further investigations. For example, results in study with small sample size and without randomization might not be satisfactory. Researchers in England conducted six monthly intervention sessions allowing 36 children and young adolescents with mental and developmental difficulties to develop green space at school under the guidance of horticulturists and psychotherapist. However, the quantitative outcomes regarding mental wellbeing were not satisfactory in this pre and posttest design [41]. A RCT with larger sample size is warranted. In terms of other benefits, previous RCT also hypothesized that school gardening intervention, in combination with coordinated approach in school-based interventions, might promote healthy eating, physical activity and improve weight status in elementary students [42]. However, the results later published did not find significant differences in outcomes such as vegetable preference, exposure, intake and fruit intake between intervention groups and the control intervention (Coordinated School Health) [43]. That means the differences in outcomes between targeted gardening intervention and no intervention remain unclear and require further trials.

\section{Conclusions}

In this study, the school based green space programme was found feasible for early adolescent students with statistically supported results of green facility use in the community and school gardening, as well as gender differences which echoed the findings in the literature. Limitations have also been identified and future study with larger scale, more frequent intervention, longer follow-up and RCT design are required. Nevertheless, our new findings support the implementation of integrating hydroponic planting techniques into the conventional planting to promote students' mental health at secondary schools. In the 
context of contemporary adolescent development, education should be holistic and should not be confined to academic achievement; additional out-of-classroom experiential learning activities that enable students to learn in real-life contexts, broaden their horizons and foster whole-person development should be encouraged. In the future, the implementation of the integrated health green space programme with hydroponic planting in urban area could be a sustainable mode of promoting green space concepts and greenness exposure to benefit key stakeholders such as adolescents, schools and families.

\section{Abbreviations}

AR1: first order autoregressive

DASS: depression anxiety stress scale

G6PD: glucose-6-phosphate dehydrogenase

GEE: generalized estimating equations

I-CVI: item content validity index

MAD: median absolute deviation

QoL: quality of life

RCT: randomized controlled trial

SES: socio-economic status

VAS: visual analogue scale

\section{Declarations}

\section{Ethics approval and consent to participate}

Ethical approval for this study was obtained (ID: HSEARS20160618002) from the Human Subjects Ethics Sub-Committee of The Hong Kong Polytechnic University. The study methods were carried out in accordance with the Declaration of Helsinki as well as the guidelines and regulations of the SubCommittee. Information sheets and parental consent forms outlining the details of the program were distributed to recruit students. This ensures participating students and their parents or guardians understood the potential risks and benefits of participation in the study. They were also informed of the rights to withdraw from the study at any time. Students who did not obtain parental informed consents were not included. Informed consent was also sought at the school level from a representative of each participating school. Both school representatives and participants were informed that data would be analyzed anonymously and in aggregate. At the end of the program in each school, all students received information and resources of counselling and mental health services. 


\section{Consent for publication}

Not applicable.

\section{Availability of data and materials}

The datasets used and/or analysed during the current study are available from the corresponding author on reasonable request.

\section{Competing interests}

The authors declare that they have no competing interests.

\section{Funding}

This research was funded by Lee Hysan Foundation under the Service Learning Project in Collaborative Care in School Health and Safety. The funding body has no role in the design of the study and collection, analysis, and interpretation of data and in writing the manuscript.

\section{Authors' contributions}

Authors' contributions are the followings: Conceptualization: CSTW and YKC; Methodology: CSTW and YWM; Validation: CSTW and YWM; Formal Analysis: APYC, CSTW, YWM and SWHK; Investigation: LKPS, EK and CKCW; Resources: YKC and LKPS; Writing-Original Draft Preparation: CSTW, EK, CKCW, APYC and SWHK; Writing-Review \& Editing: APYC, LKPS and SWHK; Supervision: CSTW; Project Administration: CSTW and YKC; Funding Acquisition: CSTW and YKC. All authors read and approved the final manuscript.

\section{Acknowledgements}

We would like to thank Dr Man Kin Wong, Dr Sau Fong Leung, Dr. Kin Cheung and Dr. Winsome Lam for the validation of the content and questionnaires. We gratefully acknowledge the support from Ms. Renee Leung who monitored the progress of the program.

\section{References}

1. Perry DG, Pauletti RE: Gender and adolescent development. Journal of Research on Adolescence 2011, 21(1):61-74.

2. Lau JTF, Gross DL, Wu AMS, Cheng K-m, Lau MMC: Incidence and predictive factors of Internet addiction among Chinese secondary school students in Hong Kong: A longitudinal study. Social Psychiatry and Psychiatric Epidemiology 2017, 52(6):657-667.

3. Loke AY, Mak Y-w, Wu CST: Characteristics of influential peers in the eyes of secondary school students: A mixed method study. Primary Health Care Research \& Development 2017, 18(5):429-440. 
4. Leung MC, Cheung RYM: Music engagement and well-being in Chinese adolescents: Emotional awareness, positive emotions, and negative emotions as mediating processes. Psychology of Music 2020, 48(1):105-119.

5. Rydin Y, Bleahu A, Davies M, Dávila JD, Friel S, De Grandis G, Groce N, Hallal PC, Hamilton I, HowdenChapman $P$ et al: Shaping cities for health: Complexity and the planning of urban environments in the 21 st century. Lancet 2012, 379(9831):2079-2108.

6. Tost $\mathrm{H}$, Champagne FA, Meyer-Lindenberg A: Environmental influence in the brain, human welfare and mental health. Nature Neuroscience 2015, 18(10):1421-1431.

7. Stigsdotter UK, Ekholm O, Schipperijn J, Toftager M, Kamper-JøRgensen F, Randrup TB: Health promoting outdoor environments - Associations between green space, and health, health-related quality of life and stress based on a Danish national representative survey. Scandinavian Journal of Public Health 2010, 38(4):411-417.

8. Clatworthy J, Hinds J, Camic PM: Gardening as a mental health intervention: A review. Mental Health Review Journal 2013, 18(4):214-225.

9. Kam MCY, Siu AMH: Evaluation of a horticultural activity programme for persons with psychiatric illness. Hong Kong Journal of Occupational Therapy 2010, 20(2):80-86.

10. Astell-Burt T, Mitchell R, Hartig T: The association between green space and mental health varies across the lifecourse: A longitudinal study. Journal of Epidemiology and Community Health 2014, 68(6):578-583.

11. Richardson EA, Mitchell R: Gender differences in relationships between urban green space and health in the United Kingdom. Social Science \& Medicine 2010, 71(3):568-575.

12. Ode Sang $\AA$, Knez I, Gunnarsson B, Hedblom M: The effects of naturalness, gender, and age on how urban green space is perceived and used. Urban Forestry \& Urban Greening 2016, 18:268-276.

13. Janssen I, Rosu A: Undeveloped green space and free-time physical activity in 11 to 13 -year-old children. International Journal of Behavioral Nutrition and Physical Activity 2015, 12(1):26-26.

14. Feda DM, Seelbinder A, Baek S, Raja S, Yin L, Roemmich JN: Neighbourhood parks and reduction in stress among adolescents: Results from Buffalo, New York. Indoor and Built Environment 2015, 24(5):631-639.

15. Phibunwatthanawong T, Riddech N: Liquid organic fertilizer production for growing vegetables under hydroponic condition. International Journal of Recycling of Organic Waste in Agriculture 2019, 8(4):369-380.

16. Sardare MD, Admane SV: A review on plant without soilhydroponics. International Journal of Research in Engineering and Technology 2013, 2(3):299-304.

17. Hui SCM: Benefits and potential applications of green roof systems in Hong Kong. In: 2nd Megacities International Conference: 1-2 December 2006; Guangzhou, China; 2006: 351-360.

18. Akpinar A: How is quality of urban green spaces associated with physical activity and health? Urban Forestry \& Urban Greening 2016, 16:76-83. 
19. Beyer KM, Kaltenbach A, Szabo A, Bogar S, Nieto FJ, Malecki KM: Exposure to neighborhood green space and mental health: Evidence from the survey of the health of Wisconsin. International Journal of Environmental Research and Public Health 2014, 11(3):3453-3472.

20. Roe JJ, Thompson CW, Aspinall PA, Brewer MJ, Duff El, Miller D, Mitchell R, Clow A: Green space and stress: Evidence from cortisol measures in deprived urban communities. International Journal of Environmental Research and Public Health 2013, 10(9):4086-4103.

21. Ward Thompson C, Roe J, Aspinall P, Mitchell R, Clow A, Miller D: More green space is linked to less stress in deprived communities: Evidence from salivary cortisol patterns. Landscape and Urban Planning 2012, 105(3):221-229.

22. Fan Y, Das KV, Chen Q: Neighborhood green, social support, physical activity, and stress: Assessing the cumulative impact. Health Place 2011, 17(6):1202-1211.

23. Hartig T: Green space, psychological restoration, and health inequality. Lancet 2008, 372(9650):1614-1615.

24. Mäkinen K, Tyrväinen L: Teenage experiences of public green spaces in suburban Helsinki. Urban Forestry \& Urban Greening 2008, 7(4):277-289.

25. Depression Anxiety Stress Scales (DASS) [http://www2.psy.unsw.edu.au/dass/]

26. Wang K, Shi H-S, Geng F-L, Zou L-Q, Tan S-P, Wang Y, Neumann DL, Shum DHK, Chan RCK: Crosscultural validation of the Depression Anxiety Stress Scale-21 in China. Psychological Assessment 2016, 28(5):e88-e100.

27. Henry JD, Crawford JR: The short-form version of the Depression Anxiety Stress Scales (DASS-21): Construct validity and normative data in a large non-clinical sample. British Journal of Clinical Psychology 2005, 44(Pt 2):227-239.

28. Oei TP, Sawang S, Goh YW, Mukhtar F: Using the Depression Anxiety Stress Scale 21 (DASS-21) across cultures. International Journal of Psychology 2013, 48(6):1018-1029.

29. Chan RC, Xu T, Huang J, Wang Y, Zhao Q, Shum DH, O'Gorman J, Potangaroa R: Extending the utility of the Depression Anxiety Stress scale by examining its psychometric properties in Chinese settings. Psychiatry Research 2012, 200(2-3):879-883.

30. Andrews F, M. , Crandall R: The validity of measures of self-reported well-being. Social Indicators Research 1976, 3(1):1-19.

31. fisher.test: Fisher's Exact Test for Count Data [https://www.rdocumentation.org/packages/stats/versions/3.6.2/topics/fisher.test]

32. t.test: Student's t-Test [https://www.rdocumentation.org/packages/stats/versions/3.6.2/topics/t.test] 33. wilcox.test: Wilcoxon Rank Sum and Signed Rank Tests [https://www.rdocumentation.org/packages/stats/versions/3.6.2/topics/wilcox.test]

34. geeglm: Fit Generalized Estimating Equations (GEE) [https://www.rdocumentation.org/packages/geepack/versions/1.3-2/topics/geeglm] 
35. Mok MCM, Kennedy KJ, Moore PJ, Shan WP, Leung SO: The use of help-seeking by Chinese secondary school students: Challenging the myth of 'the Chinese learner'. Evaluation \& Research in Education 2008, 21(3):188-213.

36. Sit CHP, Braman OR, Kerr JH, Lindner KJ: Motivational style and actual and perceived academic performance of secondary school students in Hong Kong. School Psychology International 2013, 34(1):17-32.

37. Engemann K, Pedersen CB, Arge L, Tsirogiannis C, Mortensen PB, Svenning J-C: Residential green space in childhood is associated with lower risk of psychiatric disorders from adolescence into adulthood. Proceedings of the National Academy of Sciences USA 2019, 116(11):5188-5193.

38. van den Berg AE, Maas J, Verheij RA, Groenewegen PP: Green space as a buffer between stressful life events and health. Social Science \& Medicine 2010, 70(8):1203-1210.

39. Bloemsma LD, Gehring U, Klompmaker JO, Hoek G, Janssen NAH, Smit HA, Vonk JM, Brunekreef B, Lebret $\mathrm{E}$, Wijga AH: Green space visits among adolescents: Frequency and predictors in the PIAMA birth cohort study. Environmental Health Perspectives 2018, 126(4):1-9.

40. Bertram C, Rehdanz K: The role of urban green space for human well-being. Ecological Economics 2015, 120:139-152.

41. Chiumento A, Mukherjee I, Chandna J, Dutton C, Rahman A, Bristow K: A haven of green space: Learning from a pilot pre-post evaluation of a school-based social and therapeutic horticulture intervention with children. BMC Public Health 2018, 18(1):836-836.

42. Evans A, Ranjit N, Hoelscher D, Jovanovic C, Lopez M, Mclntosh A, Ory M, Whittlesey L, McKyer L, Kirk A et al: Impact of school-based vegetable garden and physical activity coordinated health interventions on weight status and weight-related behaviors of ethnically diverse, low-income students: Study design and baseline data of the Texas, Grow! Eat! Go! (TGEG) cluster-randomized controlled trial. BMC Public Health 2016, 16(1):973.

43. Asigbee FM, Davis JN, Markowitz AK, Landry MJ, Vandyousefi S, Ghaddar R, Ranjit N, Warren J, van den Berg A: The association between child cooking involvement in food preparation and fruit and vegetable intake in a Hispanic youth population. Current Developments in Nutrition 2020, 4(4):nzaa028. 